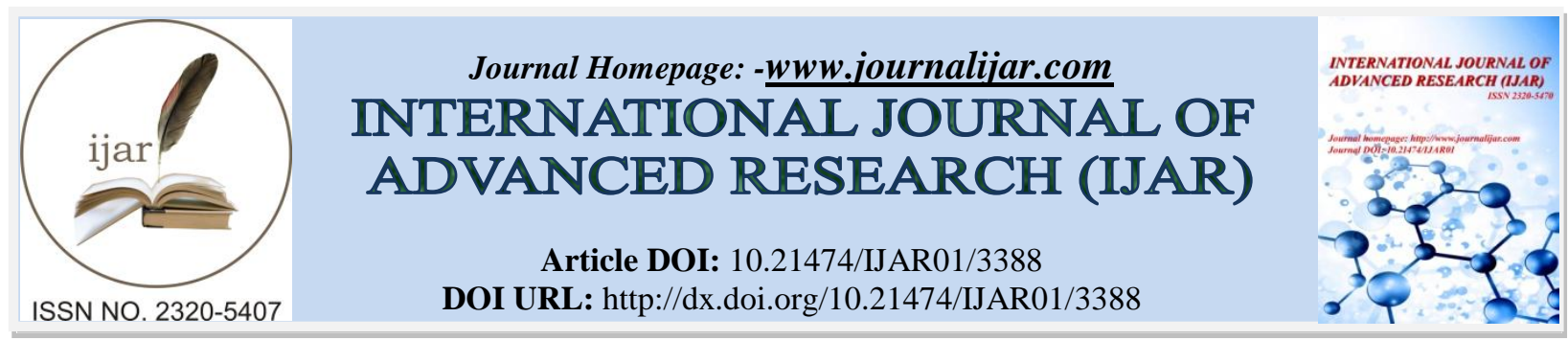

RESEARCH ARTICLE

\title{
SOME LESSONS LEARNED FROM PARTICIPATION IN STABILIZATION AND RECONSTRUCTION OPERATIONS
}

Peter Dimitrov.

\section{Manuscript Info}

Manuscript History

Received: 21 December 2016

Final Accepted: 23 January 2017

Published: February 2017

\section{Key words:-}

arms, coalition, command, conclusion, equipment, hierarchy, international peace and security, lessons, local authorities, logistics, mission, motivation, operational experience, operations, population, proposal, recommendation, relationships, satisfaction, theater, training, trucks, weapons.

\section{Abstract}

This article presents the results of a profound research in the Bulgarian Armed Forces that probed opinion of military personnel who have participated in peace support operations for the last two and a half decades. The goal of this research was to accumulate the experience of the military who took part in peace support operations, and to produce some lessons in order to improve further participation in such operations. The research team chose to do the survey by conducting interviews with military personnel who took part in peace support operations. A total of 237 military personnel were interviewed. Subsequently, the team concentrated on processing information through specialized software. There were two types of analyses - quantitative and qualitative. The results of both methods were scrutinized and compared, though the priority was given to the qualitative method. The team wrapped up the survey results in a report, distributed among military institutions and the units of the armed forces. The general conclusions of the report were that the Bulgarian Armed Forces had made significant progress in the preparation and participation in peace support operations. Military personnel who participated gained vast experience in performing different duties and responsibilities in Theaters. They performed various tasks with merit and pride and withstood difficulties of different character. During the interviews they shared willingly and openly their experience and opinion as to how to improve future preparation and performance of our units for these types of operations. Survey results came out to be more strategically and operationally geared rather than tactically orientated. The research has been highly praised and supported by the Ministry of Defense, operational HQs and units.

It turned out that although positive results were predominant there was still a lot of ground for improvement in almost all researched areas. So much so, that the research team produced a list of recommendations to improve national legislation concerning participation in peace support operations, optimization and enhancement of personnel selection and career development, raising level of ambition in operations, improving national logistics and administration, and arming and equipping the units with advanced technological items corresponding to the requirements of the contemporary operational environment. 


\section{Introduction:-}

The world is changing at a hectic pace in many aspects. Geopolitical and strategic shocks of high magnitude are determining the new world order and are altering our perceptions of conflict. Despite those changes, conflict is still ubiquitous and ever present in the pursuit of political goals by other means. Science, technology and globalization will greatly influence the nature of future conflicts. Military scholars are creating and implementing new security paradigms, such as cyber warfare, hybrid warfare, antiterrorism, etc. They predict the future dimensions and actors in conflict and military operations. However, whatever military operations will be like in the future, they will require post conflict stabilization and restoring the state of the affected country back to normal. Therefore, to achieve this end, the military will need the knowledge and know-how about dealing with the challenges of stabilization and reconstruction.

The modern trend in conflicts turned out to be a decisive operation that continues for a very short time, carried out by ad hoc coalitions followed by long and tenuous stabilization operations that produce numerous casualties, as well as the expenditure of enormous resources and political energy. This is another premise to prove the necessity of knowledge and experience from the field of stabilization and reconstruction operations. The most important weapon of the military from the battlefield is the knowledge that they gather, analyze, disseminate and implement in their future activities.

Most knowledge management experts claim that the most important and informative knowledge is tacit knowledge. They argue that while explicit knowledge comes from mere study and defines "know-what", tacit knowledge epitomizes "know-how", i.e. the results of experiential learning. Therefore it is important for the military to invent such methods and tools that make possible collecting and processing unarticulated subjective insights, judgments, and experience, which personnel acquire by participating in military operations. One of the tools that proved to be successful is the empirical study that engages the target audience and extracts tacit knowledge. As a final result it proceeds with the information and turn conclusions of the study into plausible recommendations for the leadership.

Having in mind all of the above, a team from the Defense Advanced Research Institute (DARI) adjunct of "G. S. Rakovski" National Defense College in Sofia has conducted a research and has finalized a comprehensive empirical study named "Lessons from the Participation in Operations for Support of International Peace and Security". This study was initiated as a part of a larger multinational scientific project, led by the European Research Group on Military and Society (ERGOMAS) that is taking place currently, and is scheduled to be finished by the end of this year. There are eleven countries from Europe, North and South America, Africa and Asia who participate into the project.

Particularly, the goal of the Bulgarian project was to sum up the accumulated experience of the units from the Bulgarian Armed Forces that took part in operations in support of international peace and security, and to formulate some lessons with respect to improving the manning, equipping, training, and enhancing the performance of Bulgarian military personnel in multinational operations of that type.

The research was conducted in several military units of the Bulgarian Armed Forces. The research methodology was developed on the basis of two concomitant approaches i.e. qualitative and quantitative approaches. The core of the research was a semi-structured questionnaire to lead the research team in the survey. The principal tool of the survey was an interview that followed the logic of the questionnaire. All interviews with military personnel were held on site. They were conducted with different depth, scale, span, and length as the research team took into consideration knowledge, competencies and experience of the interviewees. Data processing was done by specialized qualitative and quantitative analysis software (SPSS and En Vivo). Conclusions from the research were drawn through analyses and synthesis of the survey results. On the basis of the conclusions, the research team developed a set of recommendations, aimed at improving participation in multinational operations in support of international peace and security.

The study necessitated a lot of work (about 350 man-hours) for doing the interviews and more than two months for the analytical activities. In the course of research the team enjoyed full cooperation from the commanding officers and the surveyed personnel. 


\section{Sample of the Research:-}

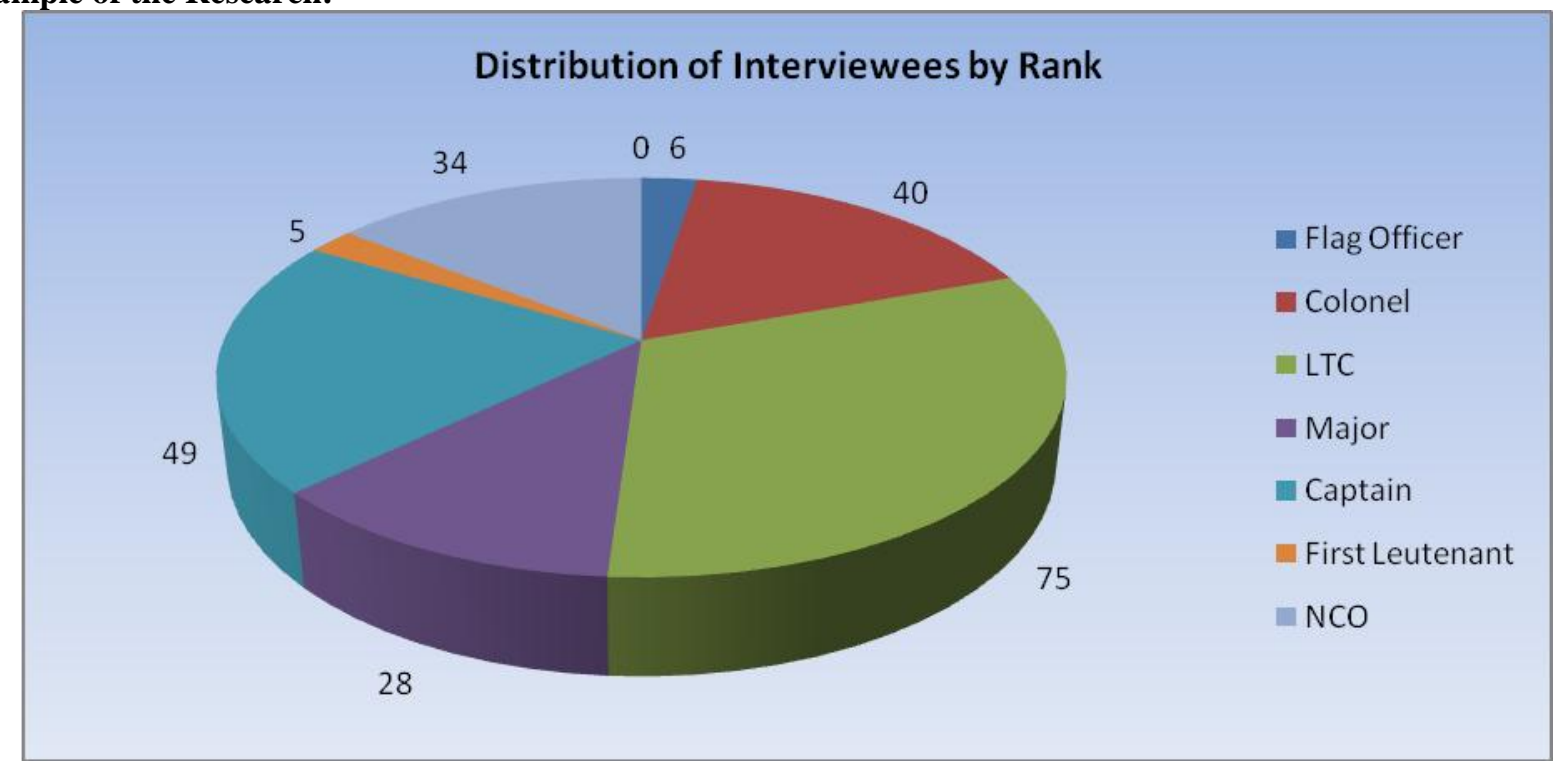

Figure 1:-

A total of 260 interviews of the surveyed personnel were taken. Some of the interviews did not provide the necessary information, so the team discarded them. There were 237 interviews that were taken into consideration for analysis. 226 of the respondents were males ( 95 percent) and there were 11 females ( 5 percent). 82 percent of the interviewees were married, and the rest were single. Many of the interviewees had participated in more than one mission, so that prior to calculations it was accepted that eachseparate participationwas taken as a single event for analysis. There were 489 events in total. Distribution of personnel by arms was as follows: Army-89 percent, Air Force-9 percent, and Navy- 2 percent. The distribution of respondents by rank is shown on Fig. 1.

The scope of the research extended from Bulgarian participation in PKO after the end of the Cold War up to 2014. Distribution of participation of Bulgarian contingents in PKO is shown on Fig.2.

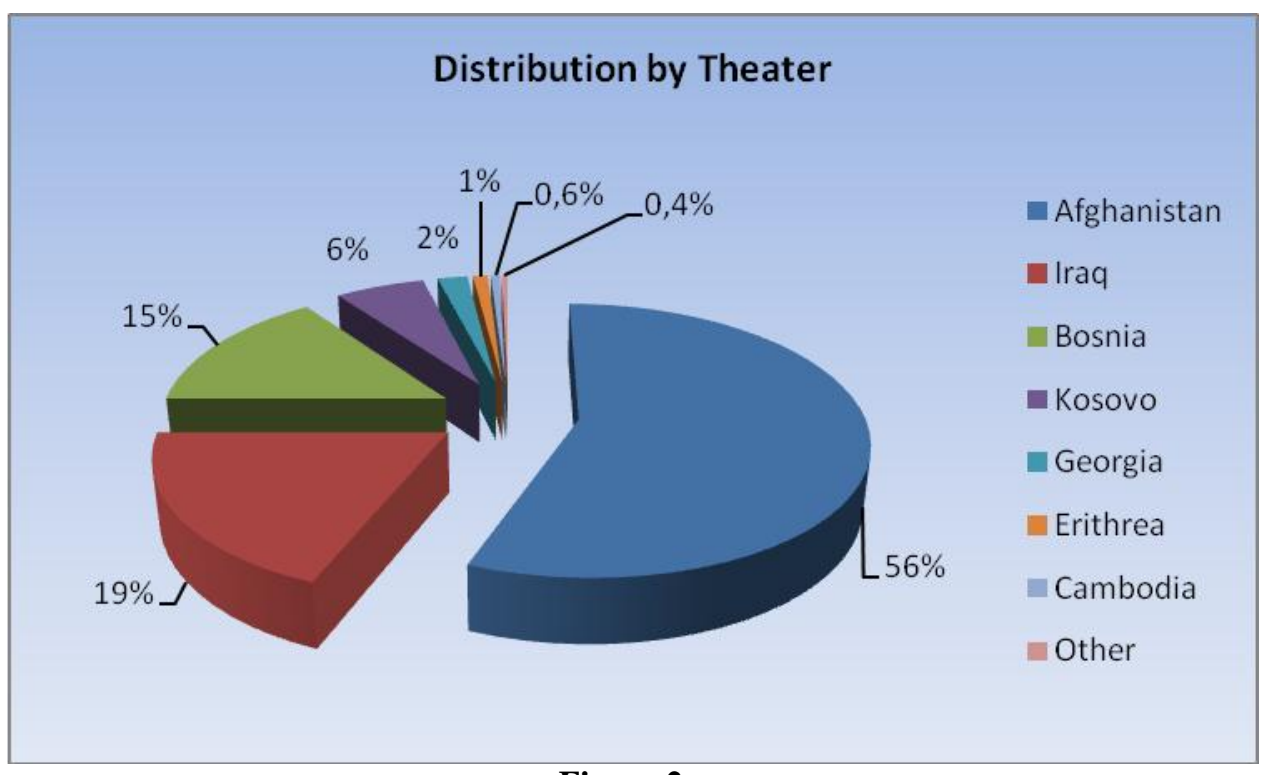

Figure 2:- 


\section{Quality of Training:-}

According to the analysis of the respondents' answers, concerning pre-deployment training, it seems that the quality of training for participation in operations in support of international peace and security has improved significantly for the last ten years. Most of the interviewees insisted that training had undergone a noticeable evolution. In the respondents' opinion, the cornerstone of this positive change was Bulgarian participation in the stabilization and reconstruction phase of operation Iraqi Freedom and the NATO mission in Afghanistan. ${ }^{1}$ The majority of respondents reiterated that our participation in these operations marked a radical change of approach to training. Planning, organization and conduct of predeployment training since then has been systemically updated and streamlined, in accordance with the specific requirements of mission tasks, as well as the conditions of their accomplishment. Interviewees shared the opinion that following 2004, new methods and forms of training of units were implemented, to quote:

- conduct of training in conditions and environment close to the real situation in missions;

- training with weapons and equipment, with real organizational structures and equipment;

- use of opposing forces during training accompanied by imitation and live firing exercises;

- use of instructors who had already taken part in similar missions;

- use of advanced forms of training of staffs through computer simulations.

Most importantly, the research team concluded the fact that the predominance of commissioned officers shared that the commanders on training sites received all rights, tools and authority to train the personnel in the manner that they deemed necessary, in order to meet the mission standards. The research concluded that it was very productive for the newly created missions for the Bulgarian Armed Forces to use mobile training teams from nations that have already participated in those missions. Another important conclusion of the research concerning training was that all respondents united around the premise that joint training on various NATO member states ranges had been extremely helpful and productive. This kind of training, according to most of the military personnel who attended it, had been vital to their real preparedness for missions. Notably, they mentioned training ranges in Germany, the Netherlands, Poland, Norway, and Romania.

Support to pre-deployment training was another issue of the research. It came to the conclusion that support has improved a lot. Respondents shared that all initial training for new missions has suffered from poor support. This applied also to some missions that alter conditions in the course of their conduct. They pointed out some drawbacks like insufficient number of vehicles to practice driving and special tactics; accepting provisions by replacing mission vehicles with substitutes, which affected training in undesirable ways; deficiencies of the special equipment, etc. Many interviewees pointed out that our training ranges did not correspond completely to the real missions' conditions and created wrong perceptions and expectations.

Some of interviewees had the opportunity to go through online pre-deployment training. They shared the opinion that this training played significant role in enhancing their knowledge about the host country, its nature, culture, the customs of the indigenous population, etc. They praised online training and admitted that it had provided most of them with the necessary information about their real duties and responsibilities. This applied mostly to officers who took part in missions in various NATO or EU headquarters.

Induction training on site was also included in research. In 47percent of the researched cases, respondents shared that they had undergone induction training in the mission area. One of the conclusions was that during the initial missions there was little or no induction training, especially when all participants received their zones of responsibility and respectively their tasks in Theater. As a result of the previous experience of allies, and lessons learned, extensive training had been implemented. In this case during rotation and hand off it was ensured that there was enough time for the incoming units to gradually become accustomed to their tasks by the "right seat rider" system with the outgoing units. This approach was highly praised by all interviewees concerned. They pointed out that this type of organization of mission hand off was highly effective for the incoming contingent. Induction training was conducted with almost all staff officers in the multinational headquarters. Many of the respondents admitted that this training helped them a lot to adapt to their real staff tasks, and gradually increase their contribution to their respective departments. They also shared the opinion that had they not undergone this smooth transition they would not have been able to perform their functional duties and responsibilities.

\footnotetext{
${ }^{1}$ Bulgaria took part in Iraq stabilization with infantry battalions and other contingents from 2003 till the end of 2008,
} and in Afghanistan from 2002 and is currently taking part in Resolute Support. 
Responses with regards to specialized training had also been taken into research considerations. The team explored how this training influenced the knowledge and skills of the trainees in improving their preparedness to deal with their respective functional duties. The majority of interviewees (78 percent) answered positively about specialized training on host country peculiarities, governance, specificity of national culture, as well as how to behave and apply intercultural communication. Most of the respondents expressed very high appreciation of countries' handouts, distributed to all personnel prior to deployment (Afghanistan, Bosnia, and Iraq). About a third of the researched personnel pointed out that specialized training for their respective position was not satisfactory enough. This applied mainly to officers who were assigned to staff positions in the headquarters of the multinational forces, ISAF HQ, or the like.

Language training was also an issue for the research. Predominance of interviewees shared that initially, once deployed to mission area military personnel faced difficulties communicating in multinational environment and with the local population. Later on, they overcame the psychological barrier, gained self-confidence and became more proficient in communicating with other nations. It was established that language training of non-commissioned personnel did not fully meet requirements.

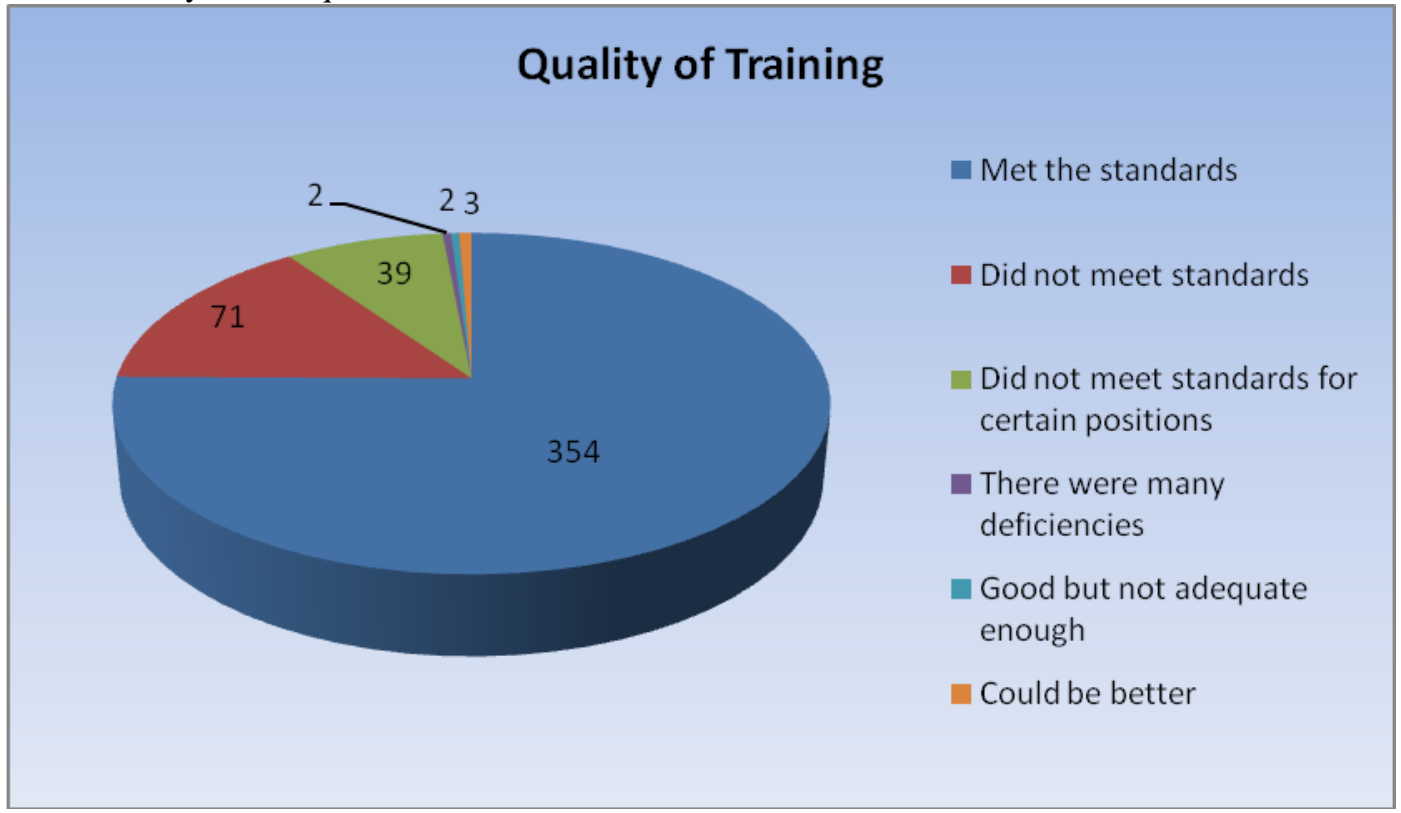

Figure 3:-

The results in Fig. 3 clearly show that in the majority of cases respondents (354, 72 percent) gave a positive assessment of pre-deployment training. They believed it was necessary to improve support of training. Interestingly enough, most of the generals and senior officers expressed the opinion that the quality of training is a function of commanders' leadership qualities.

There was an extensive research on logistic support of contingents in this study. The results of the interviews show that logistics is a key factor for the successful accomplishment of tasks. The main issues that the research team explored were related to individual clothing and equipment of the military; armament and equipment of contingents; accommodation, dining, communal services, and medical support. The team explored as separate research issues: the quality and ergonomics of clothing, and individual gear: Kevlar helmets, backpacks, flak jackets, tactical goggles, tactical vests, gloves and other equipment. The majority of respondents (Figure 4) evaluated the quality of individual equipment as good, meeting the mission requirements. One third of the respondents expressed the opinion that there were certain drawbacks in the provision of individual equipment. Every fifth respondent believed that the individual equipment of the military for the mission was not good enough. Individual clothing and footwear emerged as a central bone of contention in the research and people think that logisticians need to improve them in future. 


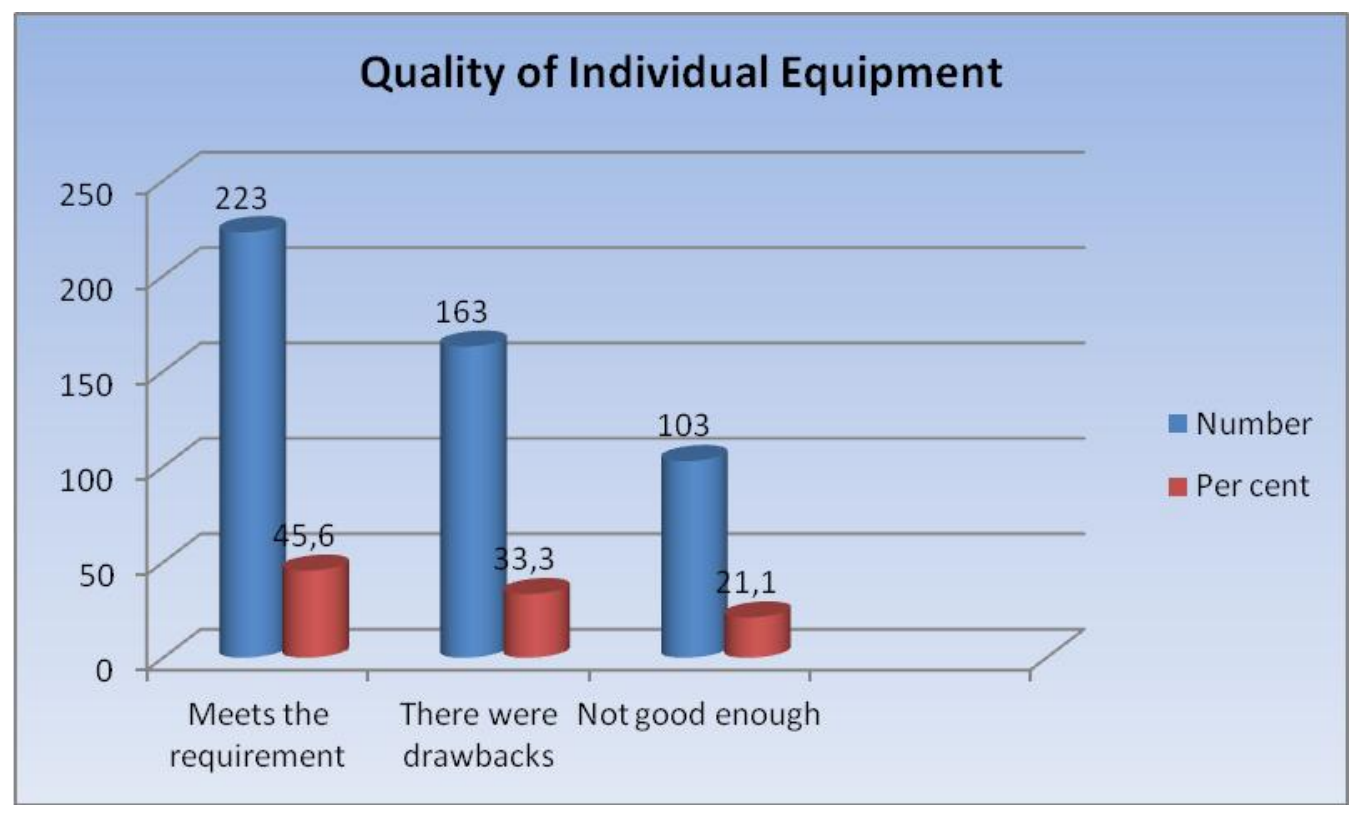

Figure 4:-

A large number of military shared their opinion that the logistic support of the contingents had undergone a positive development. They think that in the process of incremental participation of the Bulgarian Armed Forces in missions abroad the commanders and staffs that were in charge of manning, equipping and training the units had gained experience and responded adequately to the needs of contingents. Each subsequent contingent deployed wasmuch better equipped than the previous one. Some respondents shared that in most of the cases where negative assessments were given, it was due to overreaction by some of the personnel and it did not correspond to the real situation. They thought that contingents had been equipped with all the best the Armed Forces had at their disposal at that time.

The team paid particular attention in the study to personal and crew-served weapons and equipment. The majority of respondents expressed a positive opinion about armament and other crew-served equipment which they used during the missions. They estimated that the available weapons (individual and collective) had decent tactical performance and met the requirements of concurrent peace keeping operations. The same opinion was expressed about the performance of vehicles and other equipment. The interviewees shared that in most cases the equipment was in line with the mission requirements. In some missions, in Afghanistan in particular, part of the tasks was performed with equipment provided by the coalition partners, which according to respondents was also adequate for the assigned tasks.

In 28 percent of the explored cases respondents said that the armament and equipment corresponded to some degree to the missions' requirements. According to them, the tasks could be accomplished with the available weapons and equipment, but with a number of caveats. In this case assessments of weapons were more positive, rather than negative. Talking about vehicles, there were mixed feelings. Many respondents said that during the first missions (Cambodia, Bosnia, Kosovo, Iraq 1.2) they had to do their duties with available standard equipment at that time (mainly Russian - UAZ, ZIL, BRDM, GAZ, BTR-60 PB), but these were the realities, and albeit conditionally, the equipment performed adequately. Around 6 percent of the interviewees estimated that the above mentioned armament and equipment did not meet mission requirements. Some soldiers thought that the above mentioned equipment was hopelessly outdated and they performed their duties with difficulty. In Iraq and Afghanistan all vehicles and other military equipment of the coalition were equipped with diesel engines, but Bulgarian contingents were equipped with gasoline ones, so that their refueling in Theater was a challenge for logisticians. What is more they did not provide ballistic protection for personnel.

Analysis of research results for accommodation, food and communal services shows that this was one of the areas with a very high degree of approval. In 92 percent of cases the interviewees praised this type of support. There was a central support for accommodation, meals and communal services in general. As a common practice those types of 
services were included as clauses of the Memorandum of Agreement between the lead country (organization) and the rest of participants. Following the deployment accommodation, meals and communal services have been traditionally provided by civilian contractors. Typical responses of the interviewees in this area were like: "The accommodation, food and services were excellent. Everything was excellent; there was no shortage of anything, everything one wished was available. There were very good living conditions, there was air-conditioning, Internet was available, and you name it." There were, however, about 5 percent of the respondents who expressed dissatisfaction with organization of accommodation, meals and communal services. Finally, in approximately 3 percentof the cases, the military openly stated that the conditions were unsatisfactory. Further analysis made it possible to pinpoint the missions in which soldiers identify logistics as poorly organized. The gaps are most closely associated with the initial missions in Afghanistan (ISAF-1, 2, 3, 4), Iraq (SFIR 1, 2) and especially the mission in Cambodia. Medical support of contingents was widely praised by respondents.

The military who was part of the project proposed a lot of recommendations for the further improvement of logistics, such as improving the quality of clothing and footwear and procuring them for universal wear both within the country and abroad; procuring adequate individual equipment; modernization of individual arms by equipping them with night vision capabilities, modern optical sights and the like.

Taking into consideration that the country as a NATO and EU member has commitments to achieve certain capability goals, there will be a necessity for us to seriously change and improve in this area. That said it will influence the overall look of military. The opinions of respondents and analysis lead to the conclusion that the future participation of Bulgarian units in operations in support of international peace and security will require a radical improvement in the planning and logistic support.

Another central question for research in this study was the issue of relationships in missions, both in multinational environment within the framework of multinational coalitions, where Bulgarian military was involved as well as within national contingents. The link between relationships and the effectiveness of command and control was explored. Several key questions were answered, namely: hierarchy in coalitions and the degree of autonomy for independent decision making; the nature of the command relationships within coalitions; command relationships in the Bulgarian contingents, and the nature personal relationship with coalition partners from other nations and the local population on a daily basis.

The research team examined the hierarchy within the coalitions and the ability of our commanders to take independent decisions, to defend them and to put them into effect in accomplishing their units' tasks. Notwithstanding the restrictions, a majority of the commanders said they had the necessary autonomy of action in order to freely command and control their units. Some estimate that during the missions they had greater freedom of action than in everyday military life in Bulgaria. "I had a great degree of autonomy, greater than in Bulgaria." The largest group of officers (37 percent of cases) reported that they had a limited degree of autonomy for independent decision making. The reasons for this were based mostly on the fact that they occupied positions as staff officers in the multinational headquarters. One third of the respondents, mostly officers on staff positions and the majority of NCOs and soldiers reported that they worked in units in which they were not able to take independent decisions, i.e. they had held executive positions. To the fullest extent this applies to officers who held staff appointments in multinational HQs (MNF-I, MNC-I, ISAF HQ, etc.). Officers occupying such positions said that in most cases they were executive officers and fulfilled their tasks. They shared that in most of the cases they would propose something concerning the job; their proposals were not taken into consideration and remained without consequences.

The majority of respondents (almost 80 percent) evaluated the relations within the coalition as decent, wellintentioned and collegial (Fig. 5). Coalition partners demonstrated understanding, sympathy and helpfulness. In most cases, they were responsive and accurate. A significant percentage of respondents shared that there was a certain initial stage of studying each other during the mission, the so called "examination stage", and then partners treated you the way you had performed: "Initially there was a stage of study, but if you won their trust, coalition partners were very cooperative, benevolent and helpful." Another group of soldiers (5.5 percent) had the opinion that command relationships within the coalition were official (diplomatic) and reasonable subordination was observed. A very small proportion (approximately 3 percent) believed that there was an element of domination by the partners of the leading nations over the others within the coalition. For this reason, some general and senior officers proposed that Bulgaria should have a higher level of ambition and should be represented in multinational HQ proportionately 
to the contribution of troops we provide. In this way, they deemed, we would have more influential role on decision making process within the coalition.

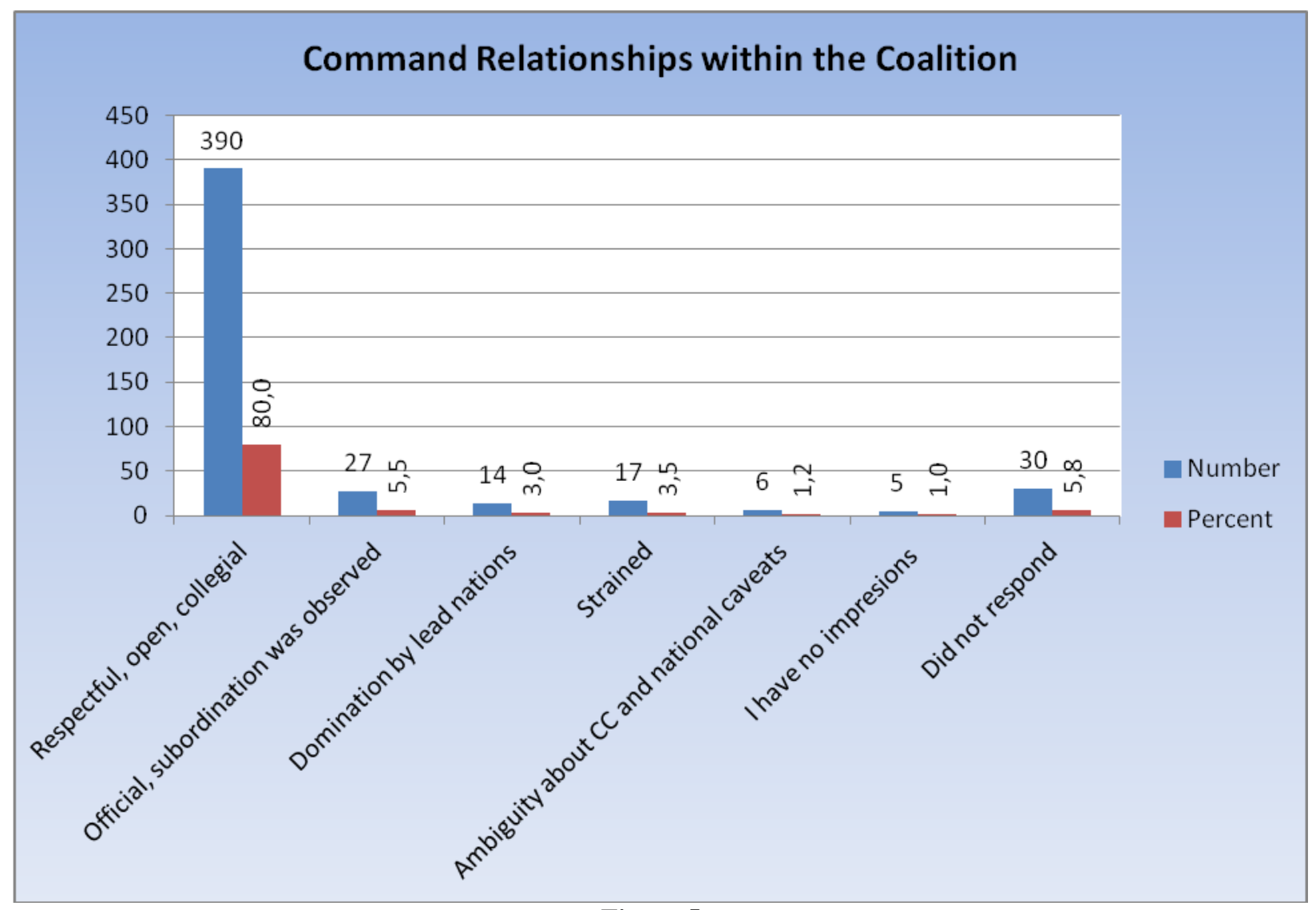

Figure 5:-

A small percentage of soldiers believed that there was tension between the Bulgarian troops and coalition partners. They think that there had been a „double standard", as a result of which there was no fair distribution of daily chores among partners in the zone of operations. Some received easier tasks, while others were charged with the most laborious and dangerous ones. Some interviewees shared that differences in perceptions of operational command and operational control often occurred, as well as misperceptions regarding capabilities and national caveats of the Bulgarian contingent.

Nearly three-quarters of respondents expressed the opinion that the relations within national contingents were good, principled and well mannered. Many of the respondents evaluated the relationships during missions as better than those in Bulgaria. They think that hardships and threats tie people together, imbue friendship, and create a common sense of responsibility, loyalty and dedication to the group. These characteristics were manifested in teams and formations and made units more cohesive. "When on a mission, people are much more disciplined and execute their duties more accurately, clearly and promptly."

According to the majority of respondents the commander plays a vital role for the morale and discipline of his (her) unit, as well as for the state of morale within the unit. He is the principle driver for the successful accomplishment of tasks. The commander strongly influences his military formation throughout the mission, especially in difficult times, when a quick and correct decision is needed. Caring for people and leading by personal example earns the trust of subordinates. "The integrity of the commander is very important. The commander must apply the principles of leadership. He should be close to his people. If he does not think and care about his people their trust evaporates very soon." 
Almost one fifth of respondents shared the opinion that morale during the missions was good. However they thought that there was not a clean line of subordination apparent, especially between the national commander and the units. This was due to distanced locations and luck of perception what was going on the site of the unit. Another small group of soldiers (about 5 percent) indicated that relations had been strained in many cases, when national commanders had taken decisions without paying attention to unit commander's opinion or considerations. This was due to the collocation of national commander and unit commander. A small group of soldiers reported that tensions had arisen once in a while when there was no fair distribution of labor within the units, i.e. some soldiers took more tasks than others.

Another field of exploration was relations with other participants in the missions, present in the same zone of responsibility. First, the team analyzed the relations with coalition partners. According to the analysis' results over two thirds of respondents (78 percent) defined relations with coalition partners as well-intentioned, honest, professional and even friendly. At the same time another group of soldiers (about 7 percent) defined relations with coalition partners as professional and polite. This group thought that in the course of working together with coalition partners relations had had a more formal and polite character, as subject to the necessary subordination and mutual respect without seeking greater proximity. There were different views expressed by nearly 9 percent of the respondents that deserve attention. These soldiers argue that there was a tendency of ,double standards" that they have felt in one way or another, taking into account the attitude of some coalition partners. Along with the prevailing positive assessments of relations with coalition partners, the analysis of the data shows that there were some negative assessments that may deserve attention. Some of them (a very small group- of less than 4 percent) said that at times, relations with the coalition partners were strained. This is mostly associated with the perception of domination attempts, arrogance, dismissive attitude and others.

The research team also investigated relations with local authorities and indigenous population. About 42 percent of the respondents reported such relations. The rest of personnel had no contacts with locals, because of the fact that they performed their duties in contained environment, or at remote sites. Most soldiers who had contacts define these relations as very good, collegial and cooperative. They worked together with understanding, cooperation and well-disposed interaction. The majority (64 percent) of the respondents indicated that they had working relationships with local armed forces in the mission area. Most of them define the relationships as collegial, very good, fair, honest and professional. Representatives of the local armed forces have shown cooperativeness and understanding. In general, they had good attitude towards the Bulgarian teams because previous teams have created a good foundation. Respondents reported that many Iraqi and Afghan troops had previous knowledge about Bulgaria and have demonstrated good feelings. A small number (less than 2 percent) of respondents said that at some point, relations with local Armed Forces were strained (green on blue accident in Afghanistan; the events in Karbala, Iraq, 2004). More than half ( 60 percent) of the respondents define their relations with the local population in the mission area as very good and normal. The attitude of Afghans to Bulgarians has been very good, unlike some other nations. Some Afghan people had ties with Bulgaria because they had graduated from Bulgarian universities, so that they preserved good memories. That is why they showed empathy and friendliness. Some soldiers shared that when they travelled throughout Afghanistan and local people saw their national flags waving on vehicles, they would raise their hands and salute. To the best of their knowledge, honesty, openness and integrity in relations were important factors for the success of the mission.

Some of the respondents suggested bringing to negotiations and planning conferences a higher level of ambition that corresponds proportionately to Bulgarian contribution to operations in support of international peace and security. According to most of them there must be an even distribution not only in numbers of troops' participation but also in key coalition positions. They support their suggestion with the argument that those who take part in these types of operations should have the leverage to take part in decision making process. Thus this would increase our share of responsibility in missions and would increase respect on the international arena.

Respondents underlined the necessity to increase the requirements for commanders' leadership qualities and professionalism. Commanders must be able to work with people, to motivate and lead them towards successful achievement of mission goals and tasks. The refinement of command relations within the contingents, keeping a clear line of command and control and strictly observing subordination, as well as enhancing the confidence of the Bulgarian military were other suggestions of the respondents. 
The research team was convinced that after exploring relationships in missions and the almost unanimous answers of the respondents, a main conclusion could be drawn, that the Bulgarian contingents performed their duties with dignity and valor. For more than two decades they have proven to be respected and reliable partners in operations in support of international peace and security.

Achievement of self-sustainment and equality in the missions and tasks accomplishment, acquisition of better armament and equipment, as well as professionalism, strengthen the self-esteem and confidence of our personnel with regards to their capabilities and in relations with the coalition partners. Openness, integrity, benevolence, tolerance and ability for intercultural communication in the mission area increase the guarantees for good relations and successful cooperation with local authorities, the armed forces of the host country and the local population.

\section{Morale and Discipline:-}

Another issue that emerged in the research as one of the most important topics was the theme of morale and discipline. In the opinion of the majority, morale proved to be the most important component of the combat power of the units and their ability to perform duties and accomplish various tasks. Data analysis has shown that the majority of the interviewed military (51percent) determined the level of morale as good. They expressed the opinion that there was a good level of morale, discipline and cohesion in the contingents there. People were ready to share the difficulties of everyday military chores and showed willingness and ability to overcome tensions that had arisen in the course of mission. Many respondents expressed the opinion that "relationships among military personnel in missions were relatively better than those back home. Dangers kept people and units cohesive and disciplined."

Another group of soldiers (38 percent) shared that the level of morale was satisfactory. They said that in general morale was good, but once in awhile it happened that certain individuals showed temporary weaknesses. Those aberrations were mended by the commanders', colleagues' and friends' aid and the affected soldiers overcame their difficulties and successfully continued to carry on their duties. According to respondents, these deviations did not significantly influence the performance of units. "Overall, the level of morale was good. There was always someone who tried to ,go astray" but the team drew him back to doing everyday duties and things got better."

A small group of respondents (6 percent) believed that morale in missions was not good enough. They thought that the level of morale of some units was rather unsatisfactory. Some interviewees recounted various isolated cases of attempts of dereliction of duties, violation of discipline and the like. They thought that these abnormalities affected negatively the image of Bulgarian contingents in the coalition and undermined national dignity. On the other hand, they shared that negative events greatly diminished the morale and discipline in units. This kind of disruption created an atmosphere of mistrust, tension and uncertainty. In those cases, they pointed out, commanders' role was crucial to mend the microclimate and alleviate the strain. Some respondents shared that morale and discipline depended greatly on the mission itself: "The nature of the mission determined the level of morale. Units were much more cohesive and people helped each other and backed one another in the toughest military missions. When on a mission there was less of a threat and there was more free time, there were more conditions for violations of any character."

The study leads to the conclusion that the Bulgarian contingents in missions demonstrate high morale and discipline. It also concluded that it were the commanders and staffs that needed to focus on improving morale and discipline, especially within the framework of participation in PKO of any type. It is necessary to make efforts in mastering the necessary command and leadership practices to maintain good organizational and psychological climate in the formations.

The research team also analyzed the degree of satisfaction of the interviewees from participation in missions abroad. The vast majority of soldiers shared their positive assessments and self-esteem. Most of respondents insisted in their feedback that they were satisfied with their participation because they had fulfilled their duties with honor and dignity and had contributed to the overall achievement of the mission's duties and tasks. According to more than 90 percent of respondents another major factor for their satisfaction was that those activities helped them enhance their professional knowledge and skills and their ability to cope with various situations in a complex environment. They believed that this was particularly important in cases where they played a vital role to help their colleagues and the whole unit to cope with missions and tasks. The positive self-esteems of the participants in missions vary depending on the issue that has proved most important to them, such as the achievement of "successful cooperation 
and mutual assistance with peers", "positive interaction in multinational environment", "good relationship with local authorities and the local population", "contribution to common mission and tasks", etc.

Commissioned officers who occupied commanding positions hold dear certain aspects of their command that raised significantly their self-assessment. In their opinion a great deal of the successful accomplishment of tasks was due to good leadership and implementation of good command practices. Most of them connect success and personal satisfaction with completion of the mission without any loss of life. "I was greatly pleased and relieved when every one of my subordinates came back safe and sound"; "I am proud that I took command of 60 people and brought all of them back home." Some respondents of this category said that it was a great relief for them that the mission had been conducted without incidents.

Another aspect of self-esteem the respondents thought very important was the organization of work, the perception of significance of soldiers' work and the positive attitude one received from international partners. The majority of interviewees shared that it was essential for them that by doing their job they contributed to overall success. This category could also include people who emphasized positive evaluation by coalition partners. They adopted the mission as a kind of personal fulfillment and self-realization.

The motivation of soldiers to take part in missions in support of international peace and security was another fundamental question of the survey. The graphs are shown on Figure 6. The research team discussed with respondents the factors that motivated them to participate in missions abroad. During the interviews, the typical factors with a high degree of recurrence emerged as follows: the challenges of the mission; opportunity to work in a multinational environment; enhancing personal knowledge and skills; proving oneself as a professional; financial benefits; to contribute to the mission; getting to know new people, places and cultures and others.

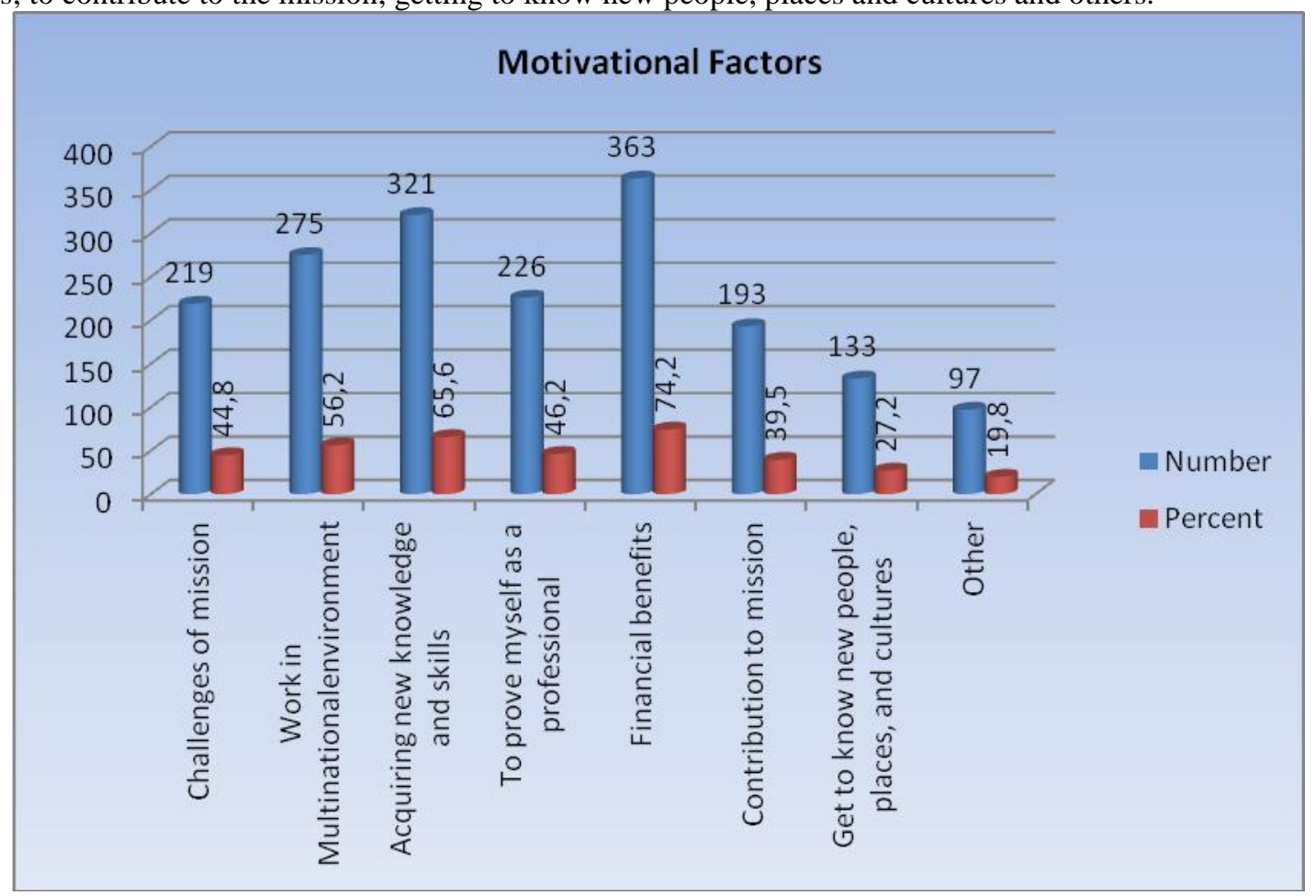

Figure 6:-

Asked if they would apply for participation in another mission, 92 percent of respondents answered, in one form or another, that they were willing to take part in missions once again. Almost all soldiers, NCOs and junior officers categorically manifested their willingness to go on a mission again. The most important factors that motivate soldiers for further participation in missions abroad are the financial benefits, the opportunity to enhance their knowledge and skills, to work in multinational environment, and to prove their professionalism. 
In the final part of the survey the research team discussed with respondents their specific proposals in the areas of research to improve the participation of our units in operations in support international peace and security. Figure 7 below shows the results of this discussion.

\section{Proposals of respondents}

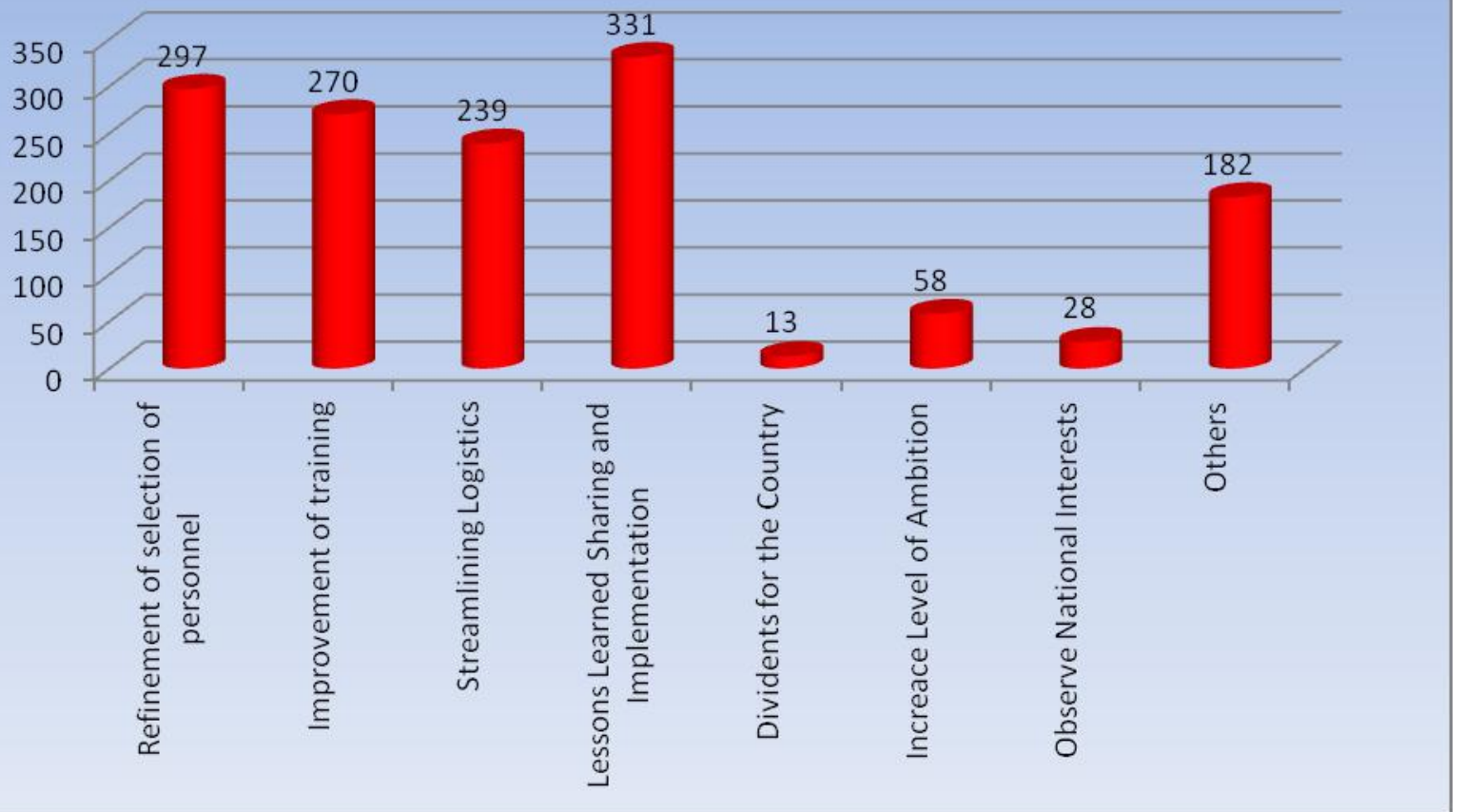

Figure 7:-

It was an opened question so that respondents might propose more than one option. Interviewees suggested reasonably that selection of personnel for participation in missions abroad should be refined; training of contingents should be improved and simulate as much as possible the real conditions of the mission; logistics and support should to be refined in order to meet missions' requirements. Most of the interviewees put a special emphasis on lessons learned sharing and their implementation in practice in order to avoid mistakes and employ the best practices. Respondents offered some proposals of strategic, institutional and administrative nature.

\section{Conclusion:-}

In conclusion the survey results demonstrated that despite the positive results from the participation of Bulgarian contingents in operations in support of international peace and security there were areas that needed development and improvement. Based on data analysis and the proposals of the respondents it was clear that there was a ground for further improvement of the preparation of contingents of the Armed Forces for participation in peace support operations. All proposals should lead to final conclusions that should be taken into consideration by the civilian and military leadership, in order to translate them into actions and reach tangible results.

\section{Bibliography:-}

1. Daniel French L.A., Winning The Peace: Building A Strategic Level Lessons Learned Program,U.S. Army War College, Carlisle Barracks, Carlisle, PA,17013-5050, 2007,

2. Davenport T.H., Prusak L., Working Knowledge. How Organizations Manage What They Know, Harvard Business School Press, Boston 1998;

3. Dr. Frank Hoffman, The Contemporary Spectrum of Conflict, index.heritage.org/military/2016/essays/contemporary-spectrum-of-conflic

4. Edgar Shein H., Organizational Culture and Leadership, San Francisco, Jossey-Bass Inc., 1997;

5. Frederick Kagan W., War and Aftermath, Policy Review, No.120

6. Giuseppe Caforio, Soldiers Without Frontiers: The View From The Ground Experiences of Asymmetric warfare, 2013 - GruppoEditoriales.r.l. Acireale - Roma; 
7. John Nagl, A Better War in Afghanistan, JFQ / issue 56, 1st quarter 2010,

8. Kristin Haugevik, Benjamin de Carvalho, Civil-Military Cooperation in Multinational and Interagency Operations, ISBN: 978-82-7002-158-1, () NorskUtenrikspolitiskInstitutt, 2007

9. Peter Senge M., The Fifth Discipline. The Art and Practice of The Learning Organization, Currency Doubleday, New York 1990, ISBN 0-385-26095-4;

10. Swee C. Goh and Peter J.Ryan, Learning Capability, Organization Factors and Firm Performance, Athens, Greece, April 5-6, 2002;

11. YantsislavYanakiev (ed.), Professional Military Education and Defense Studies: Past, Present and Future, Military Publishing House, Sofia, 2012;

12. YantsislavYanakiev, Peter Dimitrov, Interagency Cooperation in Multinational Environment, Military Publishing House, Sofia, 2012. 